\title{
COMPARTIMENTOS MORFO-PEDOGÊNICOS: POTENCIALIDADES E LIMITES NA SUSTENTAÇÃO DOS SISTEMAS DE CULTIVO E CRIAÇÃO NO MUNICÍPIO DE CANGUÇU, RS - BRASIL ${ }^{1}$.
}

\author{
Valmir Viera $^{2}$ \\ João Henrique Quoos ${ }^{3}$ \\ Roberto Verdum ${ }^{4}$
}

\begin{abstract}
Resumo
O estudo do relevo e sua relação com os solos que ocorrem na área de estudo no município de Canguçu/RS, objetiva promover uma análise detalhada e comparativa desses componentes naturais que condicionam o aumento ou a diminuição das potencialidades ou das limitações ao uso do solo no desenvolvimento dos sistemas de cultivo e criação. Para a realização do trabalho foram utilizadas imagens de satélite Quickbird (2008), trabalho de campo e de laboratório. O mapeamento, através da utilização do programa ArcGis com dados Aster GDEM - Global Digital Elevation Model que serviram para delimitar os compartimentos geomorfológicos associados aos tipos de solos, resultou no mapa em escala 1:50.000. Dessa forma, nesse município, apesar de ter sido identificado apenas um compartimento geomorfológico (Planalto), pode-se subdividi-lo em relevo de Cristas e relevo de Colinas. Observa-se a ocorrência de Solos Litólicos associados aos afloramentos rochosos e ao relevo de Cristas; Solos Regossolos Eutróficos e Solos Podzólicos Bruno-Acinzentados Eutróficos (Argissolos) localizados no relevo de Colinas e solos Hidromórficos Cinzentos Eutróficos e Aluvial nas planícies próximas a rede de drenagem. Nesse sentido, identificou-se, nos resultados preliminares, que os solos localizados em relevo de Cristas sustentam, principalmente, os sistemas cultivo do fumo, do feijão e do milho que sofrem severas restrições em função da declividade, da baixa profundidade do solo, bem como, da sua pouca fertilidade. Nesse mesmo compartimento identificou-se o sistema de criação de gado bovino de leite. Já os solos localizados nas áreas de relevo de Colinas sustentam os cultivos do milho, da soja, do feijão e a citricultura, principalmente, bem como o sistema de criação de gado de corte e de leite.

Palavras-chave: Geografia. Geomorfologia. Solo. Sistemas de Cultivo. Sistema de Criação e Desenvolvimento Agrícola.
\end{abstract}

\section{INTRODUÇÃO}

A leitura da história da espécie humana passa necessariamente pela análise da complexa relação homem-natureza. Desde os primórdios de sua evolução o homem estabelece com a natureza relações que vão da submissão, medo e respeito às mais extremas formas de antropocentrismo, desrespeito e utilitarismo no sentido de usufruir

\footnotetext{
${ }^{1}$ Resultados preliminares da tese de doutorado em andamento em Geografia na UFRGS.

${ }^{2}$ Aluno do Doutorado - UFRGS. Email: valviera@yahoo.com.br

${ }^{3}$ Mestrando de Geografia - UFSM. Email: jhquoos@gmail.com

${ }^{4}$ Professor Orientador - UFRGS. Email: verdum@ufrgs.br
} 
dos recursos naturais para atender às insaciáveis demandas de necessidades socialmente construídas.

Segundo Defumier (1996), o desenvolvimento rural é em primeiro lugar, um encadeamento de transformações técnicas, ecológicas, econômicas e sociais. Convém entender a sua dinâmica passada e as suas contradições presentes para prever as tendências futuras.

Nenhuma outra atividade econômica desenvolvida pela humanidade expressa melhor os conflitos e as alterações nessa relação do que a atividade agropecuária, por ser ela não apenas uma atividade econômica, como também reprodutiva, na medida em que do seu sucesso ou insucesso depende a sobrevivência do homem.

Segundo Christofoletti (1995), o surgimento e a evolução do homem como agente modelador que interfere no meio em que se insere em função da sua organização social, tornou-o um poderoso agente modificador da superfície terrestre. Tais modificações que ocorrem por meio de suas atividades podem ser sentidas em nível global, regional e principalmente local.

A rápida degradação dos ecossistemas sob exploração antrópica, especialmente nos países tropicais em desenvolvimento, despertou nas últimas décadas, a preocupação com a preservação e a sustentabilidade da exploração agrícola.

As áreas de incompatibilidade do uso da terra correspondem às áreas utilizadas de maneira inadequada, para fins de pecuária extensiva e atividades agrícolas, onde não são respeitadas as limitações físico-naturais de ambientes vulneráveis. Como exemplo, as áreas com relevo fortemente inclinado ou áreas de solos pouco espessos e, por conseguinte, suscetíveis à erosão.

Sendo assim, segundo Lepsch (2002) a exploração agrícola dos solos deve ser feita conforme princípios conservacionistas, levando-se em conta os aspectos econômicos e também os relativos ao meio. Portanto, o uso da terra deve ser programado antecipadamente, de modo que ocorra de maneira racional. Ou seja, deve ser concebido na perspectiva do meio natural e, não apenas na esfera econômica, como se observa recorrentemente na utilização espontânea da terra sem considerar-se nenhum condicionante físico do meio, como o relevo, a natureza do solo. Mas, considerando-se, simplesmente, o fato de se alcançar patamares mais elevados de produção. 
Portanto, o solo é um componente fundamental do ecossistema terrestre, passível de ser degradado em função do uso inadequado pelo homem, bem como, das características morfopedológicas. Por isso, o conhecimento das características físicas do relevo e o tipo de solo é fundamental para subsidiar o uso e a ocupação das terras a fim de manter a produtividade biológica, a qualidade ambiental e a vida vegetal e animal saudável na superfície terrestre.

Além do relevo, o conhecimento da forma de ocupação da terra, quanto à sua natureza e localização, é importante para programar o desenvolvimento agrícola, econômico e social de um país, região ou neste caso particular, do município de Canguçu.

Por fim, relações do meio com as atividades antrópicas são constantemente tachadas de "deterministas"; termo que carrega estigmas históricos desde Ratzel, no século XIX. Não obstante, é inegável que há uma clara influência das características físico-naturais na localização e na distribuição espacial das atividades agrícolas no município de Canguçu. Além disso, sabe-se que a disponibilidade de recursos financeiros e de novas técnicas possibilita melhores condições de cultivo, mesmo em espaços anteriormente tidos como inaptos.

Para refletir sobre essa realidade (responder a essas questões), elegeu-se como área de investigação o município de Canguçu, localizado na Metade Sul do Estado do Rio Grande do Sul, inserido entre os oito municípios elencados na matriz de estudo dentro do PROINTER - PGDR, (2002).

A escolha da área de estudo justifica-se em função das características que apresenta no contexto do desenvolvimento da região. Canguçu é um município de grande contraste na estrutura fundiária: possui uma das maiores concentrações de minifúndios do país e ao mesmo tempo parte de sua área agrícola é ocupada por médias e grandes propriedades, principalmente pela pecuária extensiva de corte.

Da mesma forma, a área de estudo apresenta um significativo envelhecimento da população rural, uma diminuição da população jovem e consequentemente um deslocamento desta população à área urbana.

Nesse sentido, como objetivo central, buscou-se identificar e mapear as potencialidades e as restrições quanto ao seu uso e sugerir práticas de manejo dos solos 
que ao mesmo tempo causem a mínima degradação e apresentem o máximo rendimento econômico.

\section{MATERIAIS E MÉTODOS}

\subsection{LOCALIZAÇÃO E CARACTERIZAÇÃO DA ÁREA DE ESTUDO}

A área de estudo foi assim selecionada, devido à importância que o relevo exerce na localização e no desenvolvimento dos sistemas de cultivo e de criação no município de Canguçu, RS - Brasil, localizada na Metade Sul do Rio Grande do Sul de acordo com a figura 1 .

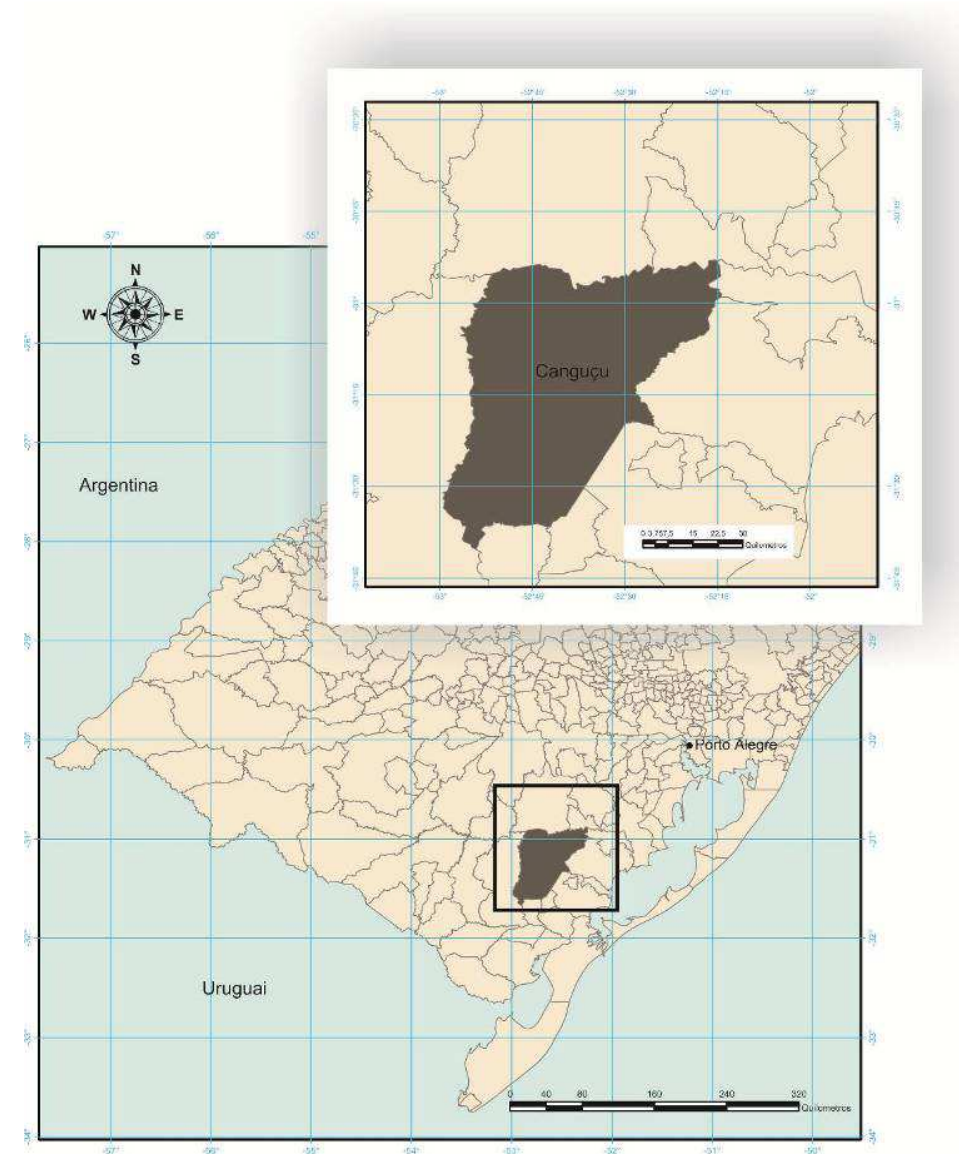

Figura 1: Localização da área de estudo

Nesse contexto, insere-se o município de Canguçu que apresenta condição econômica bem distinta, ou seja, encontra-se em situação de estagnação ${ }^{15}$. Observa-se

\footnotetext{
${ }^{1}$ Representa uma taxa de crescimento e de densidade demográfica menor que a média do Estado do Rio Grande do Sul que é de 0,0 até $4,18 \%$, indicando uma tendência de estagnação.
} 
que na área de estudo, os agricultores desenvolvem diversos sistemas de cultivo e de criação que estão distribuídos segundo a ocorrência do relevo e de solos, como pode ser observado na figura 2 .

\subsection{METODOLOGIA E COLETA DOS DADOS}

Os procedimentos metodológicos foram baseados em uma densa revisão bibliográfica sobre o tema. Foram analisados textos de diversas correntes teóricas e diversos campos do conhecimento, como geografia, agronomia e economia. Tal fato decorre da busca por uma abordagem transdisciplinar acerca da problemática.

Os dados físicos representados pelos compartimentos geomorfológicos e tipos de solos, bem como, da ocorrência dos diferentes sistemas de cultivo e de criação foram coletados através do uso de imagens de satélite, cartas topográficas, mapas de solos e visita a campo por meio de utilização de GPS onde foi utilizado o programa Arc Gis e o Modelo Digital de Terreno SRTM para a delimitação dos compartimentos geomorfológicos e os tipos de solos que ocorrem na área de estudo.

Para uma maior representação do relevo foi traçado um segmento $A-B$, no sentido Sul-Norte, que abrangeu as porções mais extensas do município em estudo. Após, os dados foram tabulados e geraram os mapas com os compartimentos geomorfológicos e respectivos tipos de solos, bem como as informações necessárias à elaboração dos resultados da pesquisa.

\section{RESULTADOS E DISCUSSÃO}

$\mathrm{Na}$ área de estudo, as propriedades são pequenas, geralmente em torno de $10 \mathrm{a}$ 20 ha (EMATER - Canguçu, 2010) e sempre apresentam algum tipo de restrição agrícola. Desta forma o espaço, na maioria das propriedades onde se pratica a agricultura e pecuária, é meticulosamente ordenado.

Em função do tipo de solo, da disponibilidade de água e da disposição do relevo, os agricultores ordenam o espaço, coordenam os diferentes usos e cultivos sabendo o que cultivar e onde cultivar, resultando em um mosaico de sistemas de cultivo.

Observa-se uma condição de distribuição e desenvolvimento dos sistemas de cultivo com relação aos solos, diferenciados se comparada aos demais municípios 
pesquisados (8). No Município de Canguçu, especificamente, quanto aos compartimentos geomorfológicos está representado pelo grande compartimento Planalto o qual foi subdividido em Cristas e Colinas, características físicas estas, peculiares que estão diretamente ligadas às condições litológicas - o município está do ponto de vista geológico, localizado sobre o Escudo Cristalino.

No subcompartimento geomorfológico Colinas identifica-se a ocorrência de mais de um sistema de cultivo e criação, ou seja, localizam-se as culturas do fumo, do milho, do feijão, da soja e do arroz - Planície Aluvial do Rio Camaquã ao Norte do município, e pomares de frutíferas (principalmente ao Sul do município), assim como a criação de gado bovino, tanto de leite como de corte, na forma extensiva, figura 2.

Após a análise e discussão dos resultados e em função das informações e imagens obtidas a campo, pode-se construir os mapas de localização e ocorrência dos compartimentos geomorfológicos associados aos sistemas de cultivo e o de solos do município de Canguçu, figuras 2 e 3.

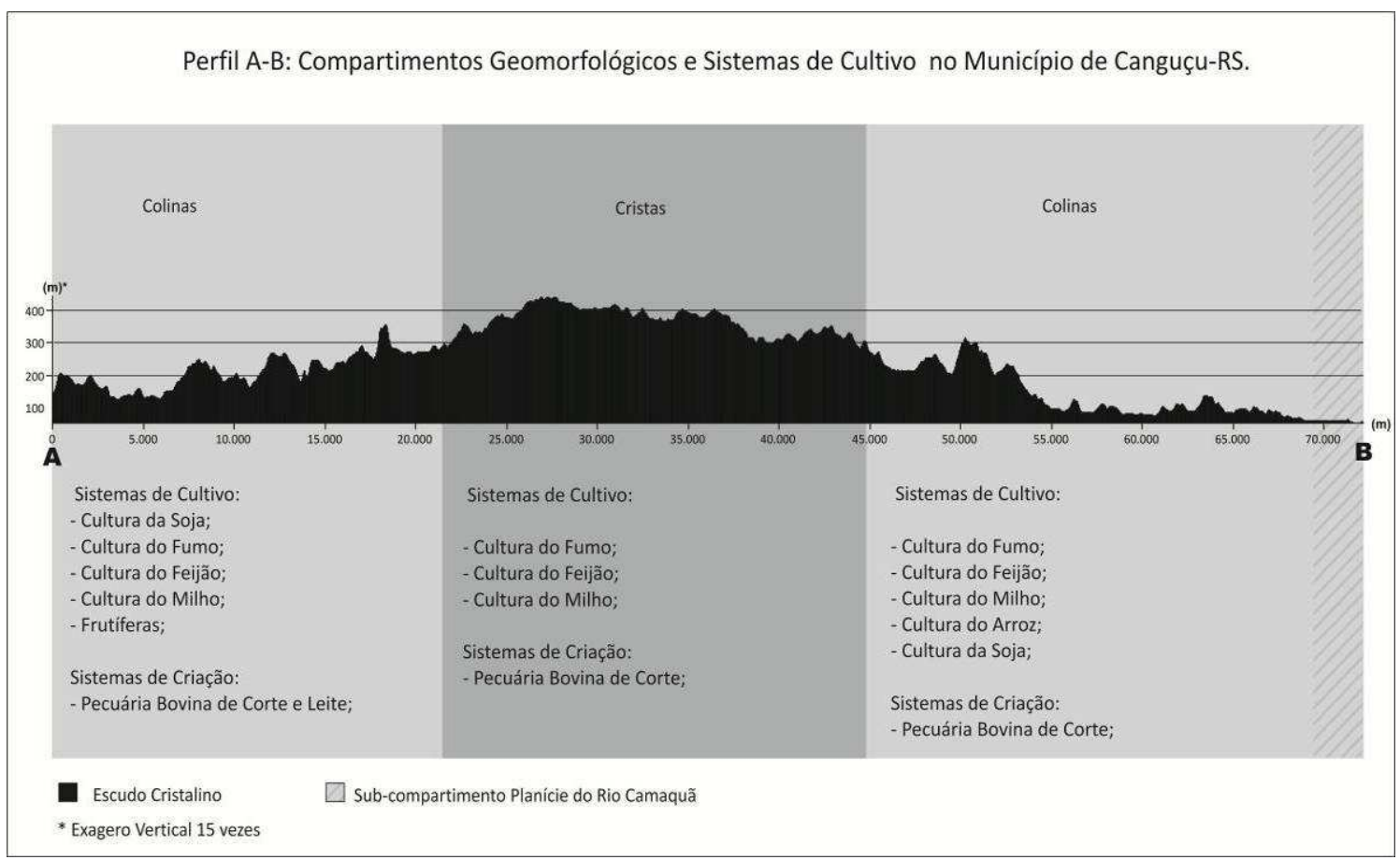

Figura 2: Formas de relevo e respectivos sistemas de cultivo e criação do município de Canguçu - RS.

Assim, pode-se considerar que o relevo não é mais um elemento limitante na localização e no desenvolvimento dos sistemas de cultivo e criação. No entanto, 
associado ao tipo de solo, o relevo influencia na grande segregação das propriedades rurais ali localizadas, desenvolvendo-se principalmente o uso a mão-de-obra familiar.

Esta heterogeneidade de sistemas de cultivo identificados neste subcompartimento está diretamente ligada à estrutura do relevo. Pois este apesar de acidentado e possuir solos rasos, o uso de novas técnicas de manejo e cultivo do solo permitiram que o homem produzisse nesse meio.

Os solos onde se desenvolvem tais sistemas de cultivo estão representados pelos Solos Podzólicos Bruno-Acinzentados Eutróficos (Argissolos) localizados no relevo de Colinas e solos Hidromórficos Cinzentos Eutróficos e Aluvial na planície aluvial do Rio Camaquã, adaptado de Cunha et. al. (1997), de acordo com a figura 3.

Já, no subcompartimento geomorfológico Cristas, observa-se o predomínio de três sistemas de cultivo principais representados pelo cultivo do feijão, do milho e do fumo, assim como pela pecuária bovina de leite, onde predomina a pequena propriedade.

Por ser uma área de relevo fortemente acidentado, restringe a atividade de cultivo a pequenas áreas destinadas a produção de milho, feijão, fumo e pêssego. As características acidentadas do terreno são melhores utilizadas com cultivos perenes, principalmente a do pessegueiro, reduzindo com isso significativamente os problemas com a degradação do solo.

Dada à localização e importância da fruticultura, essa área pode ser identificada como de agricultura/fruticultura familiar. Essa agricultura é desempenhada com o objetivo de comercializar as frutas com empresas de doces e conservas dos municípios vizinhos de Pelotas e Morro Redondo no Rio Grande do Sul.

Os solos onde se desenvolvem tais sistemas de cultivo estão representados pelos Solos Litólicos (Neossolos) com afloramentos rochosos e pelos Solos Regossolos Câmbico Eutrófico (Cambissolos), adaptado de Cunha et. all. (1997), como pode ser identificado na figura 3. 


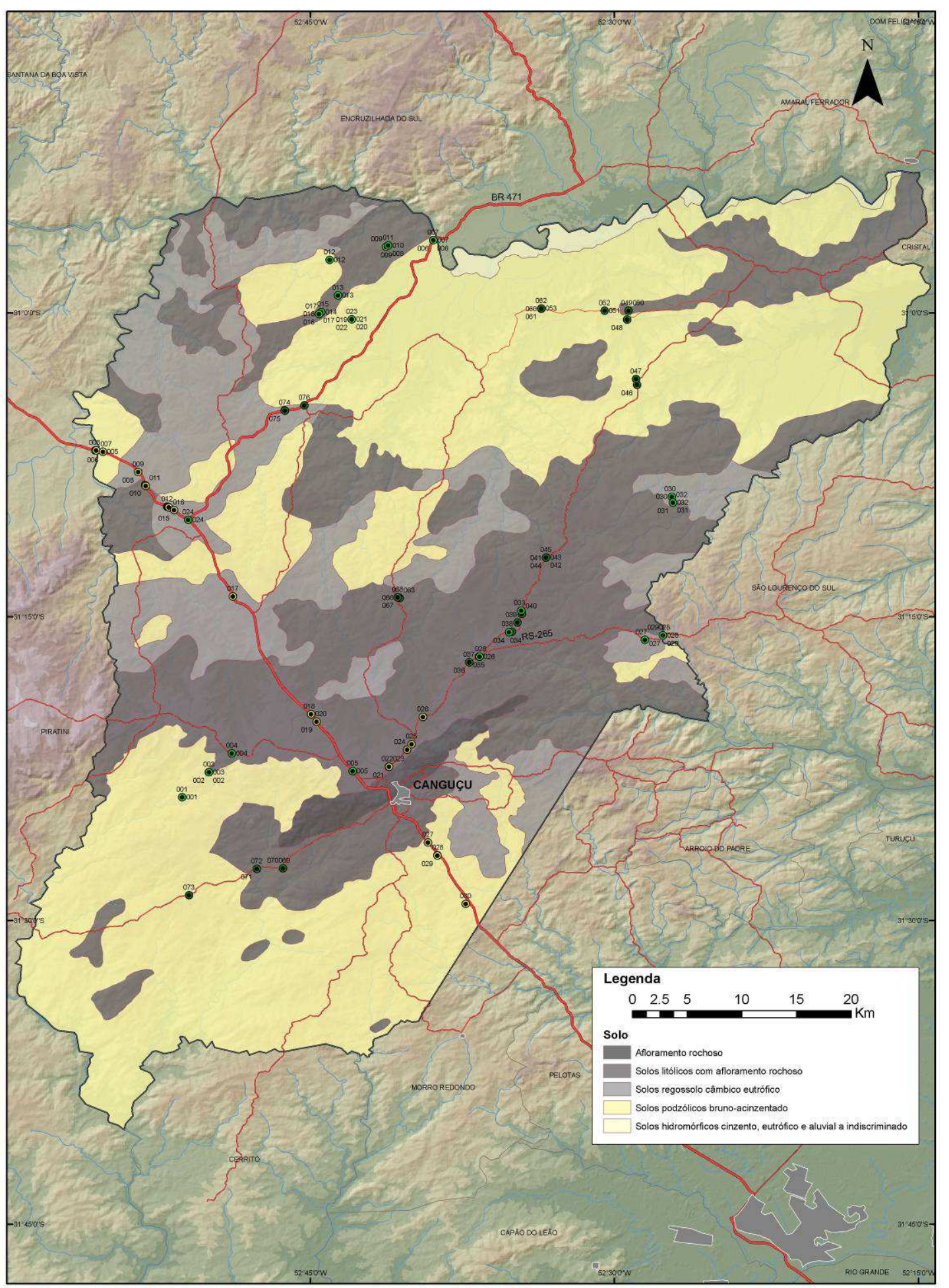

Figura 3: Mapa de solos do Município de Canguçu - RS.

Fonte: Adaptado de Cunha 1997 e trabalho de campo 2011. 
Outro elemento importante identificado e analisado é o aspecto populacional do município de Canguçu. Percebeu-se nas atividades de campo e nos dados levantados junto ao IBGE (2010) que o espaço agrário da área de estudo é um tanto complexo, figura 4.

Como já foi relatado, se por um lado é um dos municípios que apresenta uma das maiores concentrações de minifúndios no país, por outro as características morfopedológicas impõem dificuldades no desenvolvimento de determinados sistemas de cultivo, impondo restrições quanto à ocupação ordenada e completa do meio rural do município de Canguçu.

Desta forma, observa-se que com o passar do tempo, em função das características acima descritas - um tanto contraditórias - promovem um deslocamento das pessoas do meio rural para o meio urbano, principalmente os mais jovens.

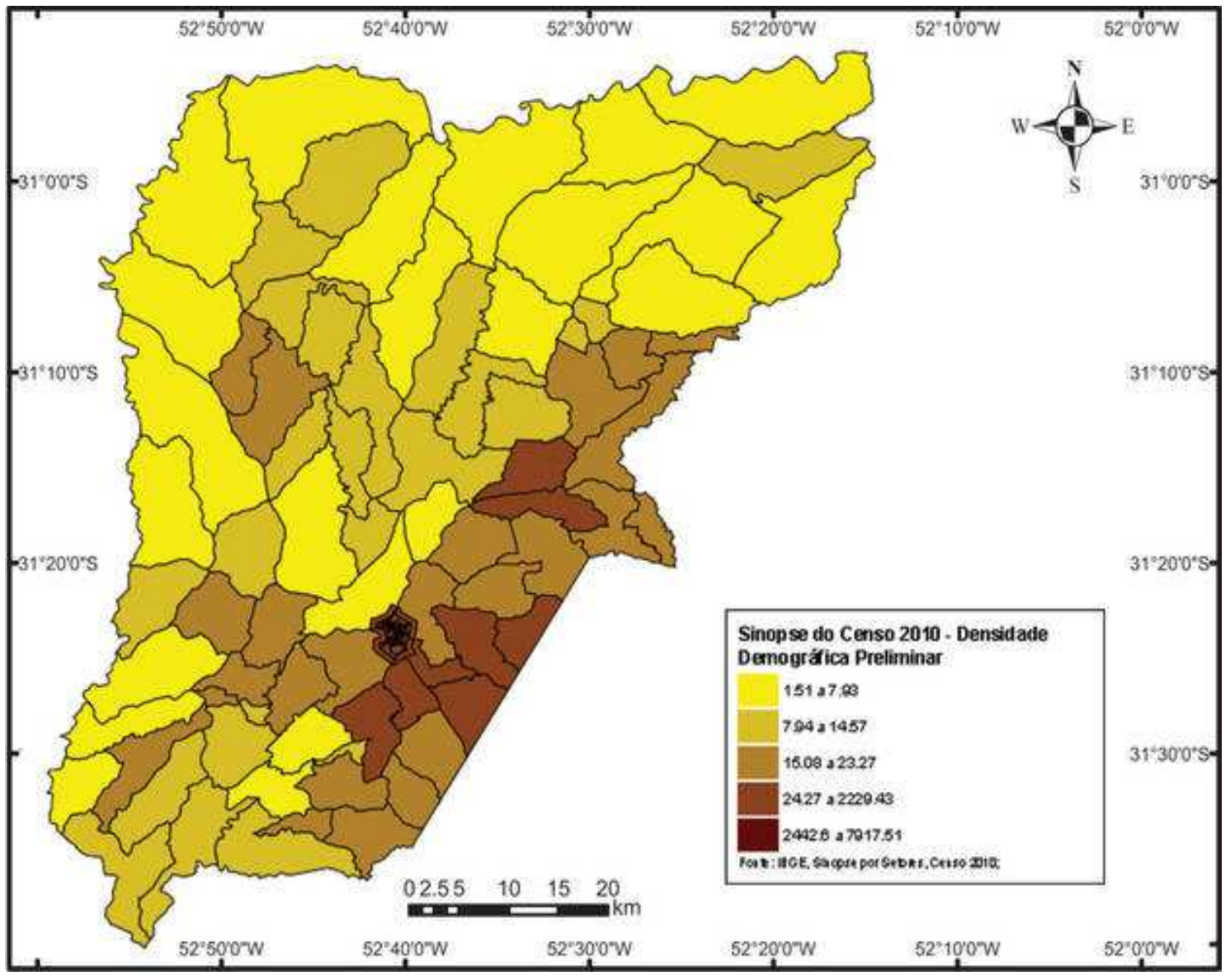

Figura 4: Mapa de densidade demográfica do Município de Canguçu - RS.

Fonte: IBGE, 2010. 
Dessa forma, ao analisarmos o mapa de densidade demográfica do município de Canguçu, fica claro que ocorre ainda neste município, um fenômeno comum na história do país, o êxodo rural, ou seja, com exceção de poucas áreas do município (porção Sul), no restante do setor rural, observa-se que há uma baixa densidade demográfica (entre 1, 51 a $\left.14,57 \mathrm{hab} / \mathrm{km}^{2}\right)$.

\section{CONCLUSÕES}

Com o passar do tempo, o homem foi se adaptando ao meio, até então inóspito ao desenvolvimento de novos cultivos e que por meio da aplicação de novas tecnologias, da incorporação de insumos que potencializam a produtividade. $\mathrm{O}$ meio físico passou de "determinante", a "condicionante" ou a "influenciador" na definição da localização e no desenvolvimento das sociedades que habitam o município da área de estudo.

Hoje, a técnica ao possibilitar a intensificação das atividades antrópicas na natureza, seja extraindo suas riquezas, seja estruturando a cultura sobre o meio, têm provocado uma mudança na localização e no desenvolvimento dos sistemas de cultivo e criação, onde se percebe que existe uma interconexão entre o meio social e o meio físico.

Portanto, pode-se afirmar que, atualmente, o relevo não é mais um elemento "determinante" e sim "influenciador" na distribuição dos sistemas de cultivo no município Canguçu. Ou seja, quando o homem passa a utilizar um novo "Itinerário técnico" de plantio e novos insumos de manejo do solo, ele passa a explorar melhor quantitativamente e qualitativamente o meio , tornando a relação sociedade-natureza mais dinâmica e intensa.

A expansão da área agrícola no município do estudo apresentou um comportamento que possui estreita relação com as suas características morfopedológicas. Foi possível verificar, por exemplo, que essa expansão foi mais significativa no compartimento morfopedológico Colinas. Trata-se de uma constatação importante, pois apesar de se observar algumas restrições físicas, é o local que se pôde identificar e mapear um maior dinamismo na implantação e no desenvolvimento de diversos sistemas de cultivos e criações. No entanto, sofreu e ainda sofre as ações de 
deterioração em suas características físico-químicas representada pela erosão e pelo assoreamento dos canais fluviais.

Nesse sentido, há uma disposição natural dos sistemas de cultivo voltados ao mercado, que se desenvolvem na área de Colinas e dos sistemas de cultivo voltados à subsistência (milho, feijão, bovino de leite - além do cultivo do fumo que nesse caso, não pode ser considerado de subsistência e sim de mercado), em que apenas o excedente é direcionado ao mercado, que se desenvolvem nas áreas de Cristas.

Além da erosão no meio rural, o contínuo revolvimento dos solos superficiais, a não adoção de técnicas conservacionistas de cultivo como as curvas de nível, a rotação de culturas, o plantio direto, agricultura ecológica (orgânica), faz com que os solos sejam lixiviados (carreados por percolação interna de água) e removidos os principais elementos nutritivos desses solos, tornando-os progressivamente estéreis à agricultura, deficiência em parte somente compensada com expressivos gastos em fertilizantes, corretivos e defensivos agrícolas.

Esta problemática acarreta em último grau, o êxodo rural. Os agricultores não vêem mais na agricultura uma perspectiva positiva de renda futura e buscam no meio urbano, uma alternativa de renda menos penosa e mais amena.

Os prejuízos para a sociedade advindos da remoção e do revolvimento dos solos superficiais no meio rural e urbano são de tal importância que estão a exigir e inspirar uma verdadeira cruzada tecnológica por sua preservação, a ser promovida pelo poder público de todos os níveis e pelos empreendimentos privados diretamente envolvidos com o problema.

\section{REFERÊNCIAS}

CASSETI, V. Ambiente e apropriação do relevo. São Paulo: Contexto, 1991.

CHRISTOFOLETTI, A. et. al. Geografia e meio ambiente no Brasil. São Paulo. HUCITEC 1995. 397 p.

CUNHA, S. B. da \& GUERRA, A. J. T. Geomorfologia e meio ambiente. Rio de Janeiro: Bertrand Brasil, 1996.

CUNHA, N. G. da.; SILVEIRA, R. J da C.; SEVERO, C. R. S.; NUNES, M. L.; SOARES, M. J; COSTA, C. das N. Estudo dos solos do município de 
Canguçu, RS. Pelotas: EMBRAPA Clima Temperado, 1997. 86p. (EMBRAPA Clima Temperado. Circular Técnica, 31).

DEFUMIER, M. Lês projets de développement agricole. Éditions Khartala - CTA Paris, 1996. 354p.

EMATER - Escritório regional no município de Canguçu. Informações coletadas no ano de 2010.

LEPSCH, Igo F. Formação e conservação dos solos. São Paulo: Oficina de Textos, 2002. 178p.

Programa de Pesquisa Interdisciplinar - PROINTER; Grupo de Pesquisa em Meio Ambiente e Desenvolvimento - GRIMAD; Programa de Pós-Graduação em Desenvolvimento Rural - PGDR, UFRGS, 2002. 55p.

STRECK, E. V. et al. Solos do Rio Grande do Sul. Porto Alegre: UFRGS, 2008. $222 \mathrm{p}$. 